\title{
Burden among Caregivers of Persons with Dementia
}

\author{
B. G. Anantharamu ${ }^{1}$, Dr. A. Thirumoorthy ${ }^{2}$, Dr. M. Senthil ${ }^{3 *}$
}

\section{ABSTRACT}

Caring for a person who has dementia is not an easy task and requires a lot of understanding and patience and it impose a lot of burden on caregivers. So this study was carried out to see the level of burden experienced by caregivers of patients with dementia. The sample comprised of 50 Caregivers of persons with dementia. The data collected from NIMHANS Geriatric Clinic. The patients who fulfilled the inclusion and exclusion criteria were identified using simple random sampling. The following tools were used for the current study: Socio-demographic data sheet and family burden interview schedule. The result found that caregivers of patients with dementia experienced mild to moderate level of burden especially in the areas of financial burden, disruption of family activities, and disruption of family life.

Keywords: Dementia, Caregivers, Family Burden,

Caregiver burden has been defined as a multidimensional response to the negative appraisal and perceived stress resulting from taking care of an ill individual. Family caregivers of people with dementia, often called the invisible second patients, are critical to the quality of life of the care recipients. The effects of being a family caregiver, though sometimes positive, are generally negative, with high rates of burden and psychological morbidity as well as social isolation, physical ill-health, and financial hardship. Caregivers vulnerable to adverse effects can be identified, as can factors which ameliorate or exacerbate burden and strain. Comprehensive management of the patient with dementia includes building a partnership between health professionals and family caregivers, referral to Alzheimer's Associations, and psychosocial interventions where indicated (Brodaty, 2009). There are an estimated 30 million people with dementia worldwide currently, and this figure is likely to double every 20 years (Ferri, 2005).

\footnotetext{
${ }^{1}$ Assistant Professor, Dept. of Psychiatric Social Work, Dharwad Institute of Mental Health and Neuro Sciences (DIMHANS), Dharwad, Karnataka, India

${ }^{2}$ Additional Professor, Dept. of Psychiatric Social Work, National Institute of Mental Health and Neuro Sciences (NIMHANS), Bangalore, India

${ }^{3}$ Psychiatric Social Worker, Dept. of Psychiatry, Post Graduate Institute of Medical Education and Research, Chandigarh, India

*Responding Author
}

(C) 2016, B Anantharamu, A Thirumoorthy, M Senthil; licensee IJIP. This is an Open Access Research distributed under the terms of the Creative Commons Attribution License (http://creativecommons.org/licenses/by/2.0), which permits unrestricted use, distribution, and reproduction in any Medium, provided the original work is properly cited. 


\section{Burden among Caregivers of Persons with Dementia}

People with dementia generally require high levels of care, most of which is provided by informal or family caregivers. Without caregivers, people with dementia would have a poorer quality of life and would need institutional care more quickly, and national economies would be swept away by the advancing demographic tidal wave.

\section{MATERIALS AND METHODS}

The population of the study included the primary caregivers of the persons diagnosed with dementia who were seeking outpatient service in NIMHANS Geriatric Clinic. The person in the patients' family who is mainly involved in providing care for most of the time during the illness and treatment period was considered as the caregiver in the current study. The data collected from NIMHANS Geriatric Clinic. The data collection was planned for a period of 4 months. The sample comprised of 50 Caregivers of persons with dementia. The patients who fulfilled the inclusion and exclusion criteria were identified and used simple random sampling. The following tools were used for the current study: Socio-demographic data sheet and family burden interview schedule.

\section{RESULTS}

Table-1: Socio demographic variables

\begin{tabular}{|c|c|c|}
\hline Variables & Frequency & Percentage \\
\hline \multicolumn{3}{|c|}{ Caregiver age classification } \\
\hline $25-35$ & 21 & $42 \%$ \\
\hline $36-45$ & 10 & $20 \%$ \\
\hline $46-55$ & 9 & $18 \%$ \\
\hline $56-65$ & 6 & $12 \%$ \\
\hline $66-75$ & 4 & $8 \%$ \\
\hline \multicolumn{3}{|l|}{ Family type } \\
\hline Joined & 14 & $28 \%$ \\
\hline Nuclear & 36 & $72 \%$ \\
\hline \multicolumn{3}{|l|}{ Religion } \\
\hline Hindu & 45 & $90 \%$ \\
\hline Muslim & 3 & $6 \%$ \\
\hline Christian & 2 & $4 \%$ \\
\hline \multicolumn{3}{|l|}{ Domicile } \\
\hline Rural & 22 & $44 \%$ \\
\hline Urban & 28 & $56 \%$ \\
\hline \multicolumn{3}{|c|}{ Educational Qualification } \\
\hline Illiteracy & 4 & $8.0 \%$ \\
\hline Primary & 10 & $20.0 \%$ \\
\hline High school & 8 & $16.0 \%$ \\
\hline PUC & 15 & $30.0 \%$ \\
\hline Graduate and above & 13 & $26.0 \%$ \\
\hline
\end{tabular}


Burden among Caregivers of Persons with Dementia

\begin{tabular}{|l|l|l|}
\hline Variables & Frequency & Percentage \\
\hline Occupation & \multicolumn{2}{l|}{} \\
\hline Business & 5 & $10 \%$ \\
\hline Farmer & 7 & $14 \%$ \\
\hline Government & 7 & $14 \%$ \\
\hline Retired government servant & 4 & $8 \%$ \\
\hline Private & 9 & $18 \%$ \\
\hline Home maker & 15 & $30 \%$ \\
\hline Unemployed & 12 & $4 \%$ \\
\hline Daily wage labourer & 1 & $2 \%$ \\
\hline
\end{tabular}

The results shows that $42 \%$ of caregiver between the age group of 25 -35 years, $20 \%$ between 36 45 years, $18 \%$ between $46-55$ years, $12 \%$ between $55-65$ years and similarly $8 \%$ of caregivers of dementia 66-75 years. In terms of family type, the study revealed that $72 \%$ of the caregivers belonged to nuclear family and $28 \%$ belonged to Joint family. In terms of religion the study sample shows that $90 \%$ of the caregivers were belonging to Hindu religion, $6 \%$ were Muslim and remaining $4 \%$ were belonging to Christian. The result suggests that the majority of caregivers $56 \%$ were from urban background and $44 \%$ of the caregivers from rural background. In terms of occupation, majority of i.e. $30 \%$ of the caregiver were homemaker, $18 \%$ were private job holder, $14 \%$ were farmers, $14 \%$ were Govt servants, $10 \%$ were business, $8 \%$ were Retd Govt servants, $6 \%$ were private job, $2 \%$ were daily wage labourer and $4 \%$ were unemployed. The result also shows that majority of the caregiver studied up to PUC 30\%, graduation and above were $26 \%$, $20 \%$ were primary , $16 \%$ were high school, and $8 \%$ were illiterate.

Table No-2: Level of Burden experienced by the Caregivers

\begin{tabular}{|l|l|l|l|l|l|l|}
\hline $\begin{array}{l}\text { Caregiver Family } \\
\text { Burden }\end{array}$ & $\mathbf{N}$ & Range & Min. & Max. & Mean & SD \\
\hline Financial Burden & 50 & 9.00 & .00 & 9.00 & 3.8400 & 2.33308 \\
\hline $\begin{array}{l}\text { Disruption in Family } \\
\text { Activities }\end{array}$ & 50 & 6.00 & 1.00 & 7.00 & 4.5200 & 1.59387 \\
\hline $\begin{array}{l}\text { Disruption in Family } \\
\text { Life }\end{array}$ & 50 & 7.00 & .00 & 7.00 & 4.0000 & 1.60357 \\
\hline Effect on Health & 50 & 7.00 & .00 & 7.00 & 1.7600 & 1.51940 \\
\hline $\begin{array}{l}\text { Effect on Mental } \\
\text { Health }\end{array}$ & 50 & 3.00 & .00 & 3.00 & .7000 & .76265 \\
\hline Subjective Burden & 50 & 2 & 0 & 2 & 1.14 & .405 \\
\hline
\end{tabular}

(C) The International Journal of Indian Psychology, ISSN 2348-5396 (e)| ISSN: 2349-3429 (p) | 46 


\section{Burden among Caregivers of Persons with Dementia}

The above table describes the level of burden experienced by the caregivers, it is seen that mean value for the financial burden was found to be $3.84(\mathrm{SD}=2.33)$ which is considered as mild burden. The mean value for disruption of family activities was found to be $4.52(\mathrm{SD}=1.59)$ and disruption of family life 4.00 ( $\mathrm{SD}=1.60$ ) which is considered as moderate level of burden.

\section{DISCUSSION}

The results show that majority the caregiver age groups between 25-35 years (42\%), caregiver were studied up to PUC (30\%) and mostly were home maker (38\%), maximum no of caregivers were belonging Hindu religion 45(90\%), caregivers were staying in urban area is 28 (56\%) , nearly three fourth 36 (72\%) of the caregivers belonged to nuclear family type. This study results match with previous study done by Rosdinom (2001) and the author found that most of the caregivers were in the middle age group (mean age of 49.23 years), about two-thirds (66.2\%) were female, majority were married (81.5\%), mostly were patients' own daughters (40\%), still employed (55.4\%), and enjoyed shared caregiving with other family members (58.5\%). Most of them had educational level up to secondary $(43.1 \%)$ and reported no financial difficulties (81.5\%).

\section{Burden of the caregivers:}

Sherwood et al., (2005) defined caregiving burden as a "multidimensional biopsychosocial reaction”, arising from the imbalance of caring demands in areas such as caregivers' personal time, social roles, physical and emotional status, financial resources, and formal care resources available for undertaking multiple roles. To investigate the perceived burden, which was assessed by the mean of the 22-item Zarit Burden Interview on dementia caregivers, Papastavrou, Kalokerinou, Papacostas, Tsangari, and Sourtzi (2007) utilized the cross-sectional study of a sample of 172 caregiver/care dyads in a study conducted in Cyprus. The results revealed that $68.02 \%$ of caregivers were highly burdened and $65 \%$ exhibited depressive symptoms. Most caregivers were daughters of people with dementia (48.3\%). Female caregivers demonstrated a higher burden than male caregivers. The burden was significantly associated with the psychopathological status of people with dementia, financial status and the educational level of dementia caregivers. Post-graduate educated caregivers experienced a lower burden than elementary school graduates. This means that carers, especially poor females with less education looking after people with dementia with more evident symptom issues are more at risk for experiencing higher perceived burden. The current study result matches with the above mentioned study and the current study result found that financial burden was found to be 3.84 $(\mathrm{SD}=2.33)$ which is considered as mild burden. The mean value for disruption of family activities was found to be $4.52(\mathrm{SD}=1.59)$ and disruption of family life $4.00(\mathrm{SD}=1.60)$ which is considered as moderate level of burden. 


\section{Burden among Caregivers of Persons with Dementia}

\section{CONCLUSION}

The result found that caregivers of patients with dementia experienced mild to moderate level of burden especially in the areas of financial burden, disruption of family activities, and disruption of family life. The current study would help the mental health professionals to enhance their existing knowledge on the understanding about the impact of the patients' illness on the caregivers. As dealing with the families of patients with mental illness is one of the important areas in provision of holistic care, this study would help them to address the above mentioned areas in a more, in depth manner. These findings also would help them to emphasize on the holistic care for the families of persons with dementia. This would enhance the overall quality of life of the caregivers of the patients with dementia and treatment outcome of the patients.

\section{Acknowledgments}

The author appreciates all those who participated in the study and helped to facilitate the research process.

\section{Conflict of Interests}

The author declared no conflict of interests.

\section{REFERENCES}

Brodaty, H., \& Donkin, M. (2009). Family caregivers of people with dementia. Dialogues in Clinical Neuroscience, 11(2), 217-228.

Ferri, C.P., Prince, M., Brodaty H., et al. (2005). Global prevalence of dementia: a Delphi consensus study. Lancet. 366: 2112-2117.

Given B, Given C. Family caregiver burden from cancer care In: Cancer nursing: A comprehensive textbook. 2. New York: Harcourt Brace; 1996. pp. 93-104.

Papastavrou E., Kalokerinou A., Papacostas S.S., Tsangari H. \& Sourtzi P. (2007) Caring for a relative with dementia: family caregiver burden. Journal of Advanced Nursing 58(5), 446-457.

Rosdinom, R., Norzarina, M. Z., Zanariah M. S., Ruzanna, Z.Z (2011). Sociodemographic Profiles of Caregivers and Their Association with Burden of Care in dementia. MJP-02-04-11.

Sherwood P, Given C, Given B, Von Eye A. 2005. Caregiver burden and depressive symptoms: analyses of common outcomes in caregivers of elderly patients. J Aging Health 17: 125-147.

How to cite this article: B Anantharamu, A Thirumoorthy, M Senthil (2016), Burden among Caregivers of Persons with Dementia, International Journal of Indian Psychology, Volume 3, Issue 4, No. 66, ISSN 2348-5396 (e), ISSN: 2349-3429 (p), DIP:18.01.158/20160304, ISBN: 978-1-365-39396-9 